\title{
Parameter Identification of Heffron-Phillips Model Considering AVR Using On- Line Measurements Data
}

\author{
B. Zaker $^{1}$, G. B. Gharehpetian ${ }^{2}$, and N. Moaddabi ${ }^{3}$ \\ ${ }^{1-3}$ Electrical Engineering Department \\ Amirkabir University of Technology \\ Tehran, Iran \\ Phone/Fax number: +0098 2164543504 \\ E-mail: zaker.behrooz@aut.ac.ir,grptian@aut.ac.ir,nimamoaddabi@aut.ac.ir
}

\begin{abstract}
The Heffron-Phillips model of the synchronous generator is a fourth order linear model including a third order synchronous machine and a first order automatic voltage regulator (AVR) model. This model is used for small signal stability analysis and power system stabilizer (PSS) design. In some power grids, the synchronous generators and excitation system parameters are not available or valid because of derating, while these parameters are essential to analyze the power systems, design the controllers, and assess the security of the network. In this paper, a genetic algorithm-based method is proposed to identify the parameters of the synchronous generator and excitation system in the frame of Heffron-Phillips model using on-line measurements data. In the proposed method, the reference voltage of AVR is considered as the input signal, while the terminal voltage and output active power of the machine are considered as output signals. The output signals are provided by phasor measurement units (PMUs). The proposed method is applied to a single machine connected to an infinite bus, to show its effectiveness and accuracy.
\end{abstract}

\section{Key words}

Synchronous generator, Genetic algorithm, Parameter identification, On-line measurements data, HeffronPhillips model.

\section{Introduction}

To understand and predict the behavior of a power system, assess its security, or any other studies, an accurate analysis of the power system is essential. The first requirement of these analyses is knowledge of parameters of different elements of the network. These elements include synchronous generators, power transformers, transmission lines, loads, etc. Since the synchronous generators play the main role in power systems, modeling and identification of their parameters have been and are an attractive and challenging research topic.

Generally, the parameter identification of the synchronous generator is classified into two approaches: off-line identification and on-line identification. In off-line identification methods, the machine is not in service. The traditional methods of the identification of parameters of the synchronous generator have been specified in IEEE standard [1]. But it had some drawbacks and in order to overcome its shortcomings some other off-line methods have been suggested such as using suddenly shorted circuit results and applying least squares method [2], exciting the stator windings with DC signal, while the rotor is in standstill [3], using stand still frequency response (SSFR) and an inverter-based voltage source [4], and etc. [5-10]. These kinds of tests are usually difficult and time consuming. The effect of the temperature and load changes has not been considered by these methods. The main drawback of these methods is that the generator must be off-grid which is not economical. To overcome the aforementioned point, online identification methods have been proposed [11-15]. The basis of on-line identification methods is the application of a small disturbance to the nominal value of the input signal. This signal should be applied to the system such that no interference occurs in the normal operation of the system. Generally, on-line identification methods can be classified into two categories; black-box modeling and white-box modeling methods. The blackbox modeling approach [15] deals with input and output data sets of the synchronous generator and the only aim is to map these sets and also, the structure of the system is arbitrary. These methods use wavelet transform, neural networks, etc. But, in white-box modeling methods [1114], the identification procedure is based on real physical structure of the synchronous machine such as third order model which is called Heffron-Phillips model. These methods use Kalman filter, Prony approach, transfer function estimation, etc. Usually, the excitation system is not considered in aforementioned methods and parameters of the excitation system has been separately identified [16-19]. But in this study, the excitation system is considered in the identification procedure.

In this paper, the synchronous generator and AVR parameters are simultaneously identified based on Heffron-Phillips model and using genetic algorithm and on-line measurement data provided by PMUs. One of the 
most important goals of the smart grids is monitoring. The PMUs are primary source of measurements for this aim and will be used widely in smart power grids. In the proposed method, the reference voltage of the AVR is considered as the input signal while the terminal voltage and output active power of the machine are considered as output signals. The aim is to identify the parameters of the system by means of matching the estimated output signals of the simulated system and measured ones of the real system using genetic algorithm. The proposed method is applied to a single machine connected an infinite bus system.

This paper has been organized as follows: a brief description of Heffron-Phillips model is presented in Section 2. The identification procedure is explained in Section 3. The case study and simulation results are described in Section 4 and finally, Section 5 concludes the paper.

\section{Heffron-Phillips Model}

A synchronous machine connected to an infinite bus which is considered as the case study in this paper is shown in Fig. 1. This system includes a power transformer and two parallel transmission lines.

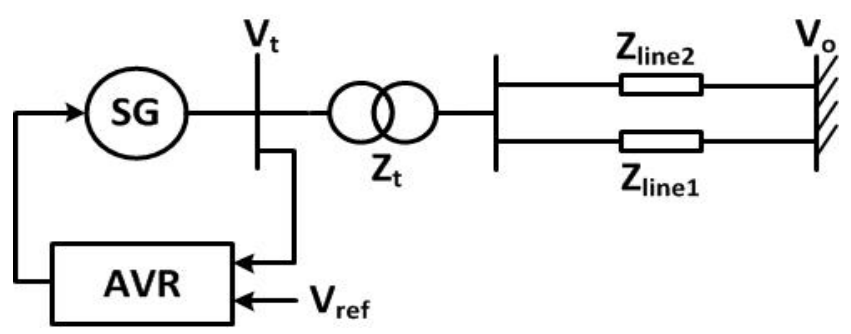

Fig. 1. Single machine infinite bus system

Generally, The Heffron-Phillips model of the synchronous generator is a fourth order linear model including a third order synchronous machine and a first order AVR. This model is suitable for small signal analysis, where linear approximation is useful. Therefore, all the input and output signals of this model have variations with a small domain around the nominal value which are shown by delta $(\Delta)$. The nonlinear equations of the machine and details of linearization procedure have been discussed in [20]. The block diagram of the linear model is shown in Fig. 2.

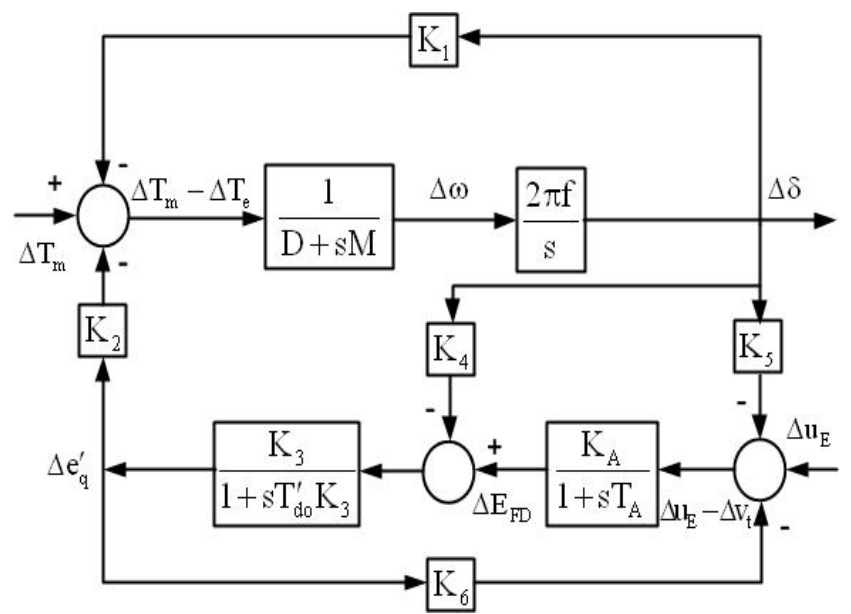

Fig. 2. Block diagram of Heffron-Phillips model
In this figure, $\omega$ is the rotor angular speed, $\delta$ is the rotor angle, $e_{q}^{\prime}$ and $E_{F D}$ are the transient and steady state internal voltage of the armature, respectively. Input signals include $U_{E}$ and $T_{M}$, which are the reference voltage of the AVR and input torque, respectively. The mechanical parameters are $D$ and $M$, which indicate the damping factor and rotor inertia, respectively. $T_{d o}^{\prime}$ is the direct axis open circuit time constant. $K_{A}$ and $T_{A}$ indicate the DC gain and time constant of the AVR.

As shown in Fig. 2, this model contains six coefficients $K_{l}-K_{6}$ called Heffron-Phillips model coefficients. The value of these coefficients is a function of the operating point and the reactances of the synchronous generator. These reactances include the steady state and transient reactance of the direct and quadratic axis (i.e., $X_{d}, X_{q}$, and $\left.X_{d}{ }_{d}\right)$. The operating point includes the terminal voltage $\left(V_{t 0}\right)$, and active and reactive power of the machine (i.e., $P_{e O}$, and $\left.Q_{e 0}\right)$. The calculation method of these coefficients is completely explained in [20].

The state-space variables and equations of this model are as follows:

$$
\begin{aligned}
& x=\left[\begin{array}{llll}
\Delta \omega & \Delta \delta & \Delta e_{q}^{\prime} & \Delta E_{F D}
\end{array}\right]^{T} \\
& u=\left[\begin{array}{ll}
\Delta U_{E} & \Delta T_{M}
\end{array}\right]^{T} \\
& y=\left[\begin{array}{ll}
\Delta V_{t} & \Delta P_{e}
\end{array}\right]^{T} \\
& \dot{x}=A x+B u \\
& y=C x
\end{aligned}
$$

where, we have:

$$
\begin{aligned}
A & =\left[\begin{array}{cccc}
-D / M & -K_{1} / M & -K_{2} / M & 0 \\
\omega_{b} & 0 & 0 & 0 \\
0 & -K_{4} / T_{d o}^{\prime} & -1 /\left(T_{d o}^{\prime} K_{3}\right) & 1 / T_{d o}^{\prime} \\
0 & -K_{A} K_{5} / T_{A} & -K_{A} K_{6} / T_{A} & -1 / T_{A}
\end{array}\right] \\
B & =\left[\begin{array}{cc}
0 & 1 / M \\
0 & 0 \\
0 & 0 \\
K_{A} / T_{A} & 0
\end{array}\right] \quad C=\left[\begin{array}{llll}
0 & K_{5} & K_{6} & 0 \\
0 & K_{1} & K_{2} & 0
\end{array}\right]
\end{aligned}
$$

The output signals which are used practically, are the terminal voltage $V_{t}$ and output active power $P_{e}$. All the values and parameters of this model are in per-unit except $T_{d o}^{\prime}, M$ and $T_{A}$ which are in second, and $K_{A}$ has no dimensión.

\section{Identification Method}

In this study, the aim is the identification of the third order synchronous generator parameters including reactances, direct axis open circuit time constant, mechanical parameters and AVR DC gain and time constant. The identification procedure is explained below:

Step 1) An operating point is considered. The terminal voltage, active power, and reactive power of the synchronous generator are measured. 
Step 2) According to the nominal value of the reference voltage of the AVR for this particular operating condition, a pseudo random binary sequence (PRBS) is applied to the AVR. The domain of this disturbance should be small in order to have a good linear approximation. $2 \%$ of the nominal value is chosen.

Step 3) The oscillation of the terminal voltage and active output power is measured.

Step 4) The Heffron-Phillips model with eight unknown desired parameters (i.e., $X_{d}, X_{q}, X_{d}^{\prime}, T_{d o}^{\prime}, M, D$, $K_{A}$, and $T_{A}$ ) is simulated. The genetic algorithm optimization procedure is used to minimize the error among measured outputs of the system and estimated outputs of the simulated system using following objective function:

$$
\text { O.F. }=\sqrt{\sum_{\mathrm{i}}\left(\underline{\mathrm{V}}_{\mathrm{ti}}-\underline{\hat{\mathrm{V}}}_{\mathrm{ti}}\right)^{2}}+\sqrt{\sum_{\mathrm{i}}\left(\underline{\mathrm{P}}_{\mathrm{ei}}-\underline{\hat{\mathrm{P}}}_{\mathrm{ei}}\right)^{2}}
$$

where, $\underline{V}_{t}$ and $\underline{P}_{e}$ are sampled vectors of measured outputs and $\underline{\hat{V}}_{t}$ and $\hat{\mathrm{P}}_{\mathrm{e}}$ are sampled vectors of estimated outputs.

Two points in the last step are important to note:

Point I. Although the reactances are not used in the Heffron-Phillips block diagram directly, but the coefficients depend on them as explained in [20] and given as follows:

$$
\begin{gathered}
K_{1}=f_{1}\left(X_{d}, X_{q}, X_{d}^{\prime}, V_{t 0}, P_{e 0}, Q_{e 0}\right) \\
K_{2}=f_{2}\left(X_{d}, X_{q}, X_{d}^{\prime}, V_{t 0}, P_{e 0}, Q_{e 0}\right) \\
\vdots \\
K_{6}=f_{6}\left(X_{d}, X_{q}, X_{d}^{\prime}, V_{t 0}, P_{e 0}, Q_{e 0}\right)
\end{gathered}
$$

Point II. According to the standards and related literature, all of the eight desired parameters have specific ranges, which are presented in the next section. Therefore, the genetic algorithm searches in these ranges.

\section{Case Study and Simulation Results}

The case study is a single machine infinite bus system as shown in Fig. 1. All simulations have been carried out in MATLAB environment. The specifications of the synchronous machine, its operating point, power transformer and transmission line are given in Table I and II.

In this study, $\Delta U_{E}$ is considered as the only input signal and $\Delta T_{M}$ is assumed to be zero. The PRBS signal (as $\Delta U_{E}$ ) is added to the nominal value of the reference voltage of the AVR. Then, it is applied to the reference point of the system as input signal and oscillations of output signals around their nominal values $\left(\Delta V_{t}\right.$ and $\left.\Delta P_{e}\right)$ are measured. White noise is added to the measured signals to make the measurements more practical and real. These signals are shown in Figs 3-5.
Table I. - Synchronous generator data

\begin{tabular}{||c|c|c|c||}
\hline \hline PARAMETER & VALUE & PARAMETER & VALUE \\
\hline Nominal Power & $50(\mathrm{MVA})$ & $D$ & 0.01 (p.u.) \\
\hline Nominal Freq. & $50(\mathrm{~Hz})$ & $K_{A}$ & 290 \\
\hline Nominal Vol. & $10.5(\mathrm{KV})$ & $T_{A}$ & 0.001 (s) \\
\hline$X_{d}$ & 2.642 (p.u) & $V_{t 0}$ & 1.00147 (p.u) \\
\hline$X_{q}$ & 2.346 (p.u.) & $P_{e 0}$ & 0.95 (p.u) \\
\hline $\mathrm{X}_{\mathrm{d}}^{\prime}$ & 0.337 (p.u) & $Q_{e 0}$ & 0.01 (p.u) \\
\hline$T_{d o}^{\prime}$ & $6.5(\mathrm{~s})$ & $V_{r e f}=U_{e 0}$ & 1.0015 (p.u) \\
\hline$M$ & $10(\mathrm{~s})$ & - & - \\
\hline
\end{tabular}

Table II. - Transformer and transmission lines data

\begin{tabular}{||c|c|c|c||}
\hline PARAMETER & VALUE & PARAMETER & VALUE \\
\hline$Z_{t}$ & 0.12 (p.u.) & $X_{L I}=X_{L 2}$ & $\begin{array}{c}0.453 \\
(\Omega / \mathrm{Km})\end{array}$ \\
\hline$R_{L 1}=R_{L 2}$ & $\begin{array}{c}0.075 \\
(\Omega / \mathrm{Km})\end{array}$ & Line length & $101 \mathrm{Km}$ \\
\hline
\end{tabular}

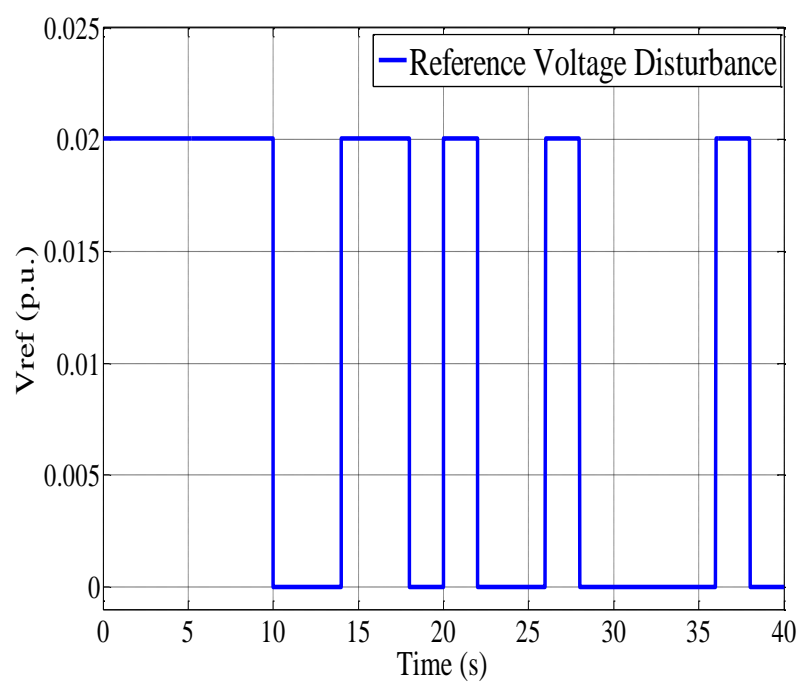

Fig. 3. PRBS signal as reference voltage small disturbance $\left(\Delta U_{E}\right)$

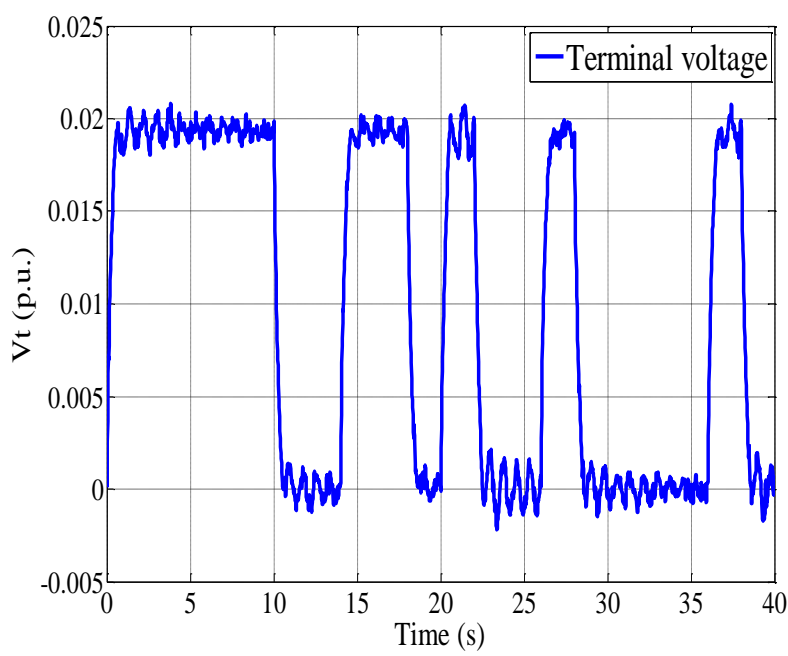

Fig. 4. Measured signal of terminal voltage $\left(\Delta V_{t}\right)$ 


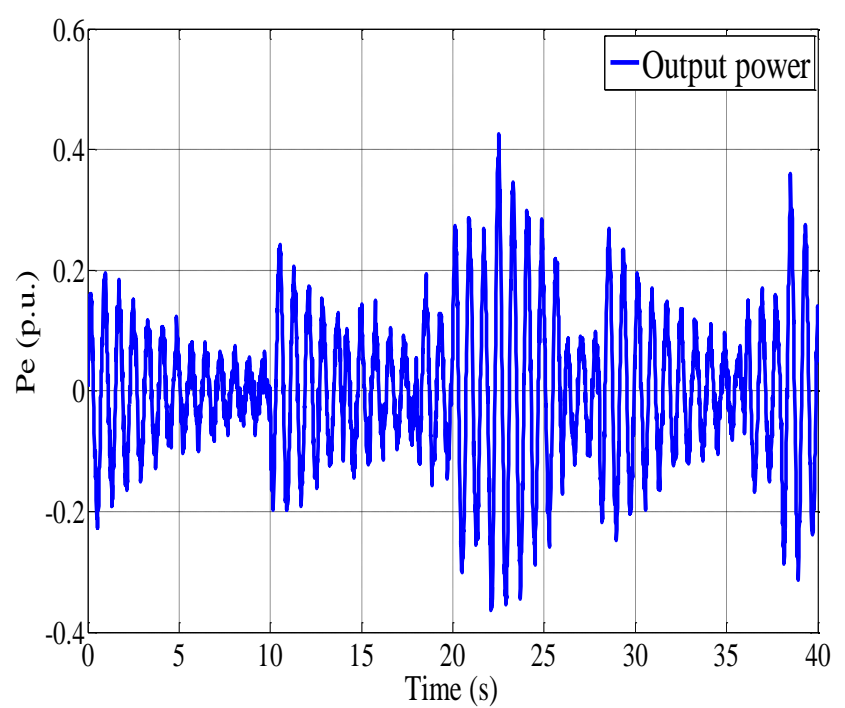

Fig. 5. Measured signal of output active power $\left(\Delta P_{e}\right)$

After that, the genetic algorithm is used to minimize the objective function, which is described by (4). The initial population is set to 20 for each parameters. The search range of each parameter discussed in Section 3, is presented in Table III. After 100 generations, the genetic algorithm is converged with the objective function value of 0.8964 . The estimated parameters are compared with real parameters in Table IV.

Table III. - The search range of parameters

\begin{tabular}{|c|c|c|c||}
\hline PARAMETER & RANGE & PARAMETER & RANGE \\
\hline$X_{d}$ & {$[1.5 \sim 3]$} & $M$ & {$[5 \sim 10]$} \\
\hline$X_{q}$ & {$[1.5 \sim 3]$} & $D$ & {$[0.001 \sim 0.1]$} \\
\hline $\mathrm{X}_{\mathrm{d}}^{\prime}$ & {$[0.1 \sim 0.6]$} & $K_{A}$ & {$[30 \sim 300]$} \\
\hline$T_{d o}^{\prime}$ & {$[5.5 \sim 8]$} & $T_{A}$ & {$[0.0005 \sim 0.5]$} \\
\hline
\end{tabular}

Table IV. - Real and estimated values of parameters

\begin{tabular}{||c|c|c||}
\hline \hline PARAMETER & REAL VALUE & ESTIMATED VALUE \\
\hline$X_{d}$ & 2.6420 (p.u) & 2.7302 (p.u) \\
\hline$X_{q}$ & 2.3460 (p.u.) & 2.3552 (p.u.) \\
\hline$X_{\mathrm{d}}^{\prime}$ & 0.3370 (p.u) & 0.3374 (p.u) \\
\hline$T_{d o}^{\prime}$ & 6.5000 (s) & 6.7163 (s) \\
\hline$M$ & 10 (s) & 10 (s) \\
\hline$D$ & 0.0100 (p.u.) & 0.0661 (p.u.) \\
\hline$K_{A}$ & 290.00 & 299.89 \\
\hline$T_{A}$ & $0.0010(\mathrm{~s})$ & $0.0012(\mathrm{~s})$ \\
\hline
\end{tabular}

The result of the genetic algorithm shows the acccuracy of the estimation. There is neglectable error in the estimation of the $K_{A}$, which considering the wide search range of this parameter, it is acceptible.
To show the effectiveness and percisoin of this identification procedure, the simulated output signlas using estimated parameters are compared with measured ones. The results are shown in Fig. 6 and Fig. 7.

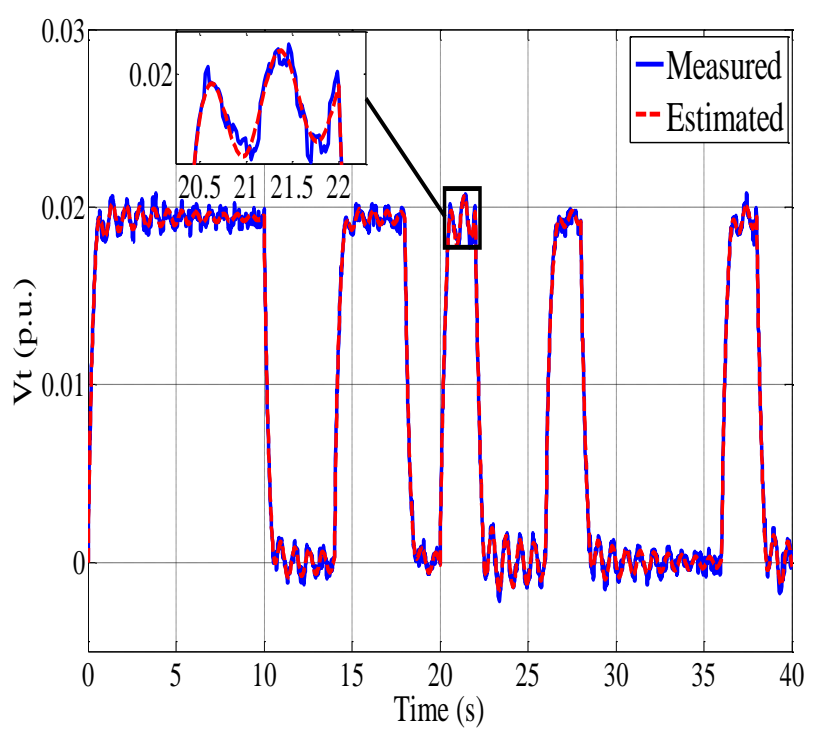

Fig. 6. Comparison of estimated and measured terminal voltage

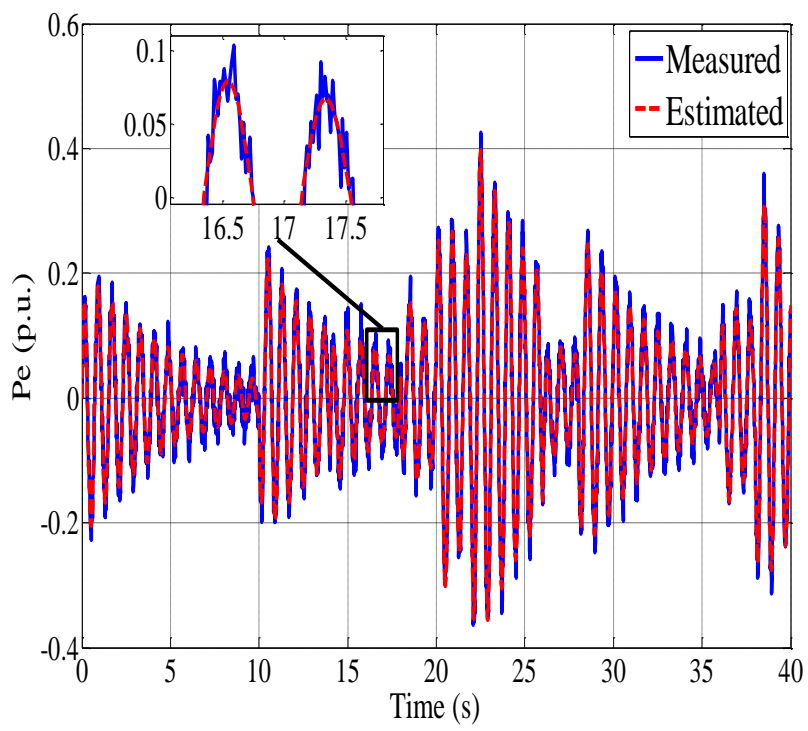

Fig. 7. Comparison of estimated and measured output active power

For validation purpose, another test has been studied. A small step of 0.05 per-unit is applied to the input mechanical torque of the synchronous generator $\left(\Delta T_{M}\right)$. It would change the operating point. During this test, $\Delta U_{E}$ is set to zero. This means that the reference voltage of the AVR has no variation and is set to the nominal value. The oscillations of the terminal voltage and output active power are measured due to this input. Also, this test is applied on the system with estimated parameters. The comparison of the measured signals and estimated ones are shown in Fig. 8 and Fig. 9. This validation test shows that the estimated parameters are valid for other operating points too. 


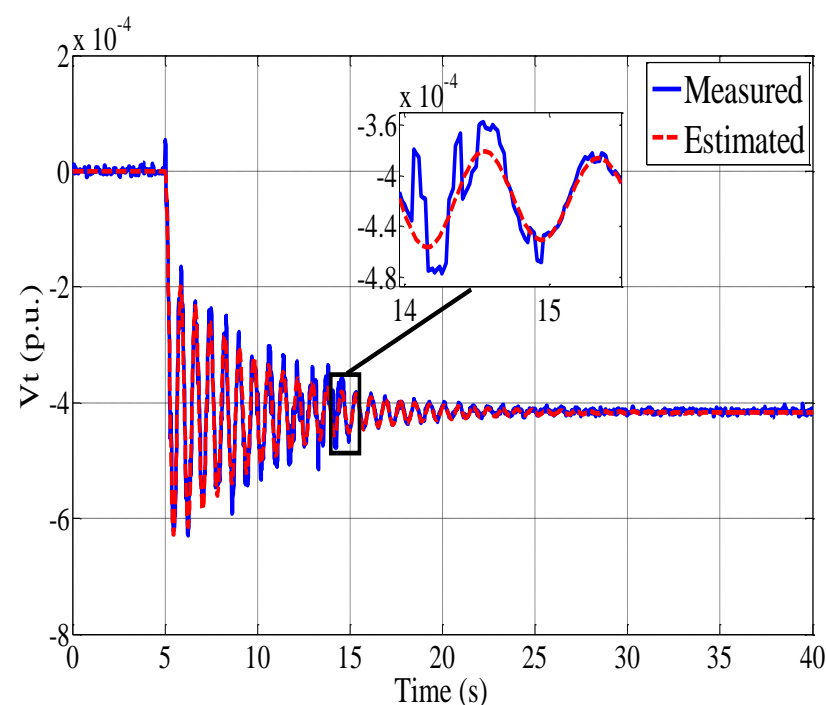

Fig. 8. Comparison of estimated and measured terminal voltage due to input torque step

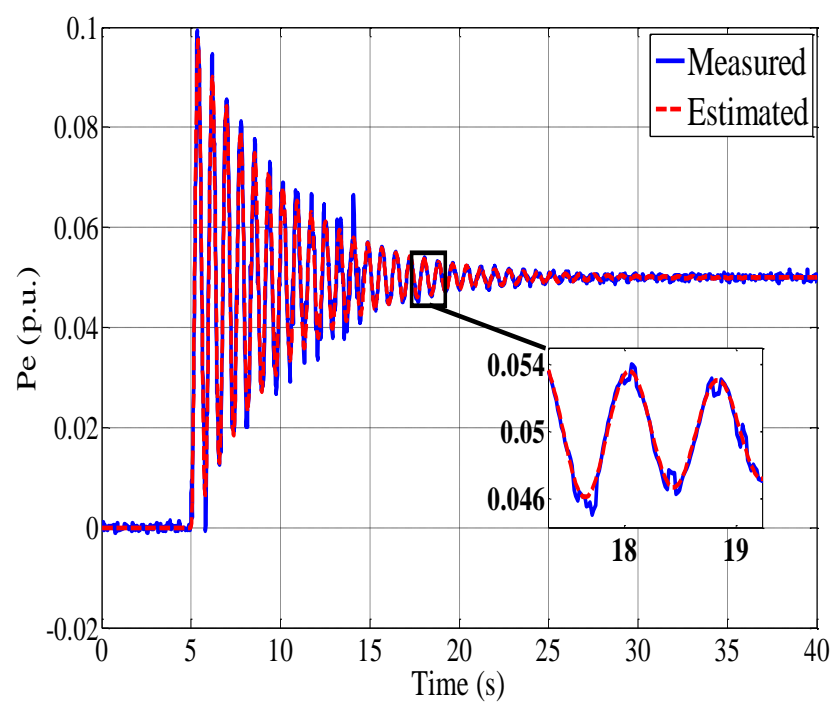

Fig. 9. Comparison of estimated and measured output active power due to input torque step

\section{Conclusion}

In this paper, the identification of parameters of the synchronous generator and excitation system in the frame of Heffron-Phillips model has been proposed using on-line measurements data and genetic algorithm. Since the smart grid concept is based on monitoring and communication infrastructures, PMUs will be used widely in these grids providing on-line measurements. These parameters are essential to analyze the power systems, design the controllers such as PSS and assess the security of the network. In the proposed method, the reference voltage of the AVR has been considered as the input signal while the terminal voltage and output active power of the machine have been considered as output signals. The proposed method has been applied to a single machine infinite bus system. The simulation results show the accuracy of the identification procedure and the validation test confirmed the validation of the estimated parameters for the various operating points.

\section{References}

[1] ANSI/IEEE Standard 115-1983, IEEE Guide: Test Procedured for Synchronous Machines.

[2] E. Mouni, S. Tnani and G. Champenois; "Synchronous generator modeling and parameter estimation using least square method", Journal of Simulation Modeling Practice and Theory, Vol. 16, pp. 678-689, 2008.

[3] M. Hasni, O. Touhami, R. Ibtiouen, M. Fadel, and S. Caux; "Estimation of synchronous machine parameters by standstill tests", Mathematics and Computers in Simulation, No. 81, pp. 277-289, 2010.

[4] T. L. Vandoorn, F. M. De Belie, T. J. Vyncke, J. A. Melkebeek, and P. Lataire; "Generation of Multisinusoidal Test Signals for the Identification of SynchronousMachine Parameters by Using a Voltage-Source Inverter", IEEE Trans. Industrial Electronics, Vol. 57, No.1, pp. 430-439, 2010.

[5] M. A. Arjona, M. Cisneros-Gonzales, and C. Hernandez; "Parameter Estimation of a Synchronous Generator Using a Sine Cardinal Perturbation and Mixed StochasticDeterministics Algorithms", IEEE Trans. Industrial Electronics, Vol. 58, No.2, pp.486-493, 2011.

[6] J. Lidenholm, and U. Lundin; "Estimation of Hydropower Generator Parameters Through Field Simulations of Standard Tests", IEEE Trans. Energy Conversion, Vol. 25, No. 4, pp.931-939, 2010.

[7] G. Shackshaft, and A.T. Poray; "Implementation of New Approach to Determination of Synchronous Machine Parameters from Tests", Proc. IEE (London), Vol. 124, No. 12, pp. 1 170- 1 178, 1977.

[8] F.P. deMello and J.R. Ribeiro; "Derivation of Synchronous Machine Parameters fiom Tests", IEEE Trans., Vol. PAS-96, pp. 1211-1218, 1977.

[9] F.P. deMello and L.N. Hannett; "Validation of Synchronous Machine Modelsand Determination of Model Parameters from Tests", IEEE Trans., Vol. PAS-100, pp. 662-672, 1981.

[10] R. Wamkeue, C. Jolette, A. B. Mpanda Mabwe, and I. Kamwa; "Cross-Identification of Synchronous Generator Parameters From RTDT Test Time-Domain Analytical Responses", IEEE Trans. Energy Conversion, Vol. 26, No. 3, pp. 776-786, 2011.

[11] M. Huang, W. Li, and W. Yan; "Estimation parameters of synchronous generators using square-root unscented Kalman filter", Electric Power System Research, Vol. 80, pp. 1137-1144, 2010.

[12] M. Dehghani, and S. K. Y. Nikravesh; "Nonlinear state space model identification of synchronous generators", Electric Power System Research, Vol. 78, pp. 926-940, 2008.

[13] M. Karrari, and O. P. Malik; "Identification of Physical Parameters of a Synchronous Generator From Online Measurments", IEEE Trans. Energy Conversion, Vol. 19, No. 2, pp. 407-415, 2004.

[14] M. Soliman, D. Westwik, and O. P. Malik; "Identification of Heffron-Phillips model parameters for synchronous generators operating in closed loop", IET Gener., Transm. and Distrib., Vol. 2, No. 4, pp. 530-541, 2008.

[15] M. Karrari, and M.B. Menhaj, "Application of different neural networks for identification of power systems," Presented at Int. Conf. Control, U.K., 2000.

[16] A. J. Saaverda-Montes, J. M. Ramirez-Scarpetta, and O. P. Malik; "Methodology to estimate parameters of an excitation system based on experimental conditions", Electric Power System Research, Vol. 81, pp. 170-176, 2011.

[17] D. C. Aliprantis, S. D. Sudhoff, and B. T. Kuhn; "Genetic Algorithm-Base Parameter Identification of a Hysteretic Brushless Exciter Model", IEEE Trans. Energy Conversion, Vol. 21, No. 1, pp. 148-154, 2006.

[18] T. Bi, A. Xue, G. Xu, X. Guo, F. Ge, and Z. Wang; "Online Parameter Identification for Excitation System based on PMU Data", $4^{\text {th }}$ International Conference on Critical Infrastructures, pp. 1-4, 2009. 
[19] M. Rasouli, and M. Karrari; "Nonlinear Identification of a Brushless Excitation System Via Field Tests", IEEE Trans. Energy Conversion, Vol. 19, No. 4, pp. 733-740, 2004.

[20] Y. Yu; Electric Power System Dynamics, Academic Press Inc., 1983. 